\title{
Sexual and Other Relationships in the Genus Agaricus
}

\author{
By CARLENE A. RAPER AND GERALDINE KAYE \\ Harvard University Biological Laboratories, Cambridge, Massachusetts 02138, U.S.A.
}

(Received 3 November 1977)

Thirty-three collections of Agaricus from nature and several strains of cultivated Agaricus bisporus were compared by 16 criteria including type of sexuality, interfertility patterns, macroscopic and microscopic morphology, growth and cultural characteristics, production of extracellular enzymes, and isoenzyme patterns for one enzyme. All but three of the collections fell into six distinct groups as defined with respect to all criteria examined. Members within each group are clearly related, but relationships between groups could not be established. Sexuality and interfertility patterns are important criteria for distinguishing relatedness among the collections. The correlations observed provide a new and useful base of reference for the classification of members of the genus Agaricus. Several aspects of the basic biology of the genus have also been revealed.

\section{INTRODUCTION}

It is particularly difficult to distinguish between members of the genus Agaricus by the classical method of comparing fruit-body characteristics. The difficulty lies in the continuous range of fruit-body types within the genus and the wide degree of variability within species. A knowledge of the basic biology of representative species would contribute to an understanding of their inter-relatedness. Such knowledge, helpful in the delineation of species, is available for only two: the famous, fully domesticated Agaricus bisporus (Lange) Imbach (Miller, 1971; Elliott, 1972; Raper, Raper \& Miller, 1972; Raper \& Raper, 1972; Miller \& Kananen, 1972), and the wild, but cultivatable Agaricus bitorquis (Quélet) Saccardo (Raper, 1976 a, $b$; Fritsche, 1976). The biology of the many other forms found in nature has remained obscure.

The purpose of this work was to clarify the relationships between members of the genus Agaricus by a comparative analysis of their biological characteristics. Type of sexuality, interfertility, nuclear number in cells, enzyme production and general growth characteristics were determined and compared for several progeny from each of 33 specimens collected from nature and for several strains of cultivated $A$. bisporus. The characteristics examined, other than fruit-body morphology, were chosen either for their relevance to breeding or for their capability of distinguishing between stocks while remaining constant among progeny within stocks. The base of reference throughout the study was the biology of the two well-defined species, $A$. bisporus and $A$. bitorquis. The analysis has permitted a new definition of groups within the genus.

\section{METHODS}

Stocks. Specimens from nature were requested from many collectors in the U.S.A. and elsewhere. A total of 38 were received, each in the form of a spore print usually accompanied by the fruit body; each specimen was identified by the collector or a collaborator. Attempts were then made to germinate the spores, and the fruit bodies were preserved by slow drying. The analysis proceeded with only those 33 specimens from which we were able to germinate spores and obtain viable progeny (Table 1). In addition, seven strains of cultivated 
Table 1. Collections of wild Agaricus

\begin{tabular}{|c|c|c|c|c|c|c|c|}
\hline $\begin{array}{l}\text { Stock } \\
\text { no. }\end{array}$ & $\begin{array}{l}\text { Collector's } \\
\text { identification }\end{array}$ & Collector & Location & $\begin{array}{l}\text { Percentage } \\
\text { germi- } \\
\text { nation }\end{array}$ & $\begin{array}{l}\text { Progeny } \\
\text { sample }\end{array}$ & $\underset{\text { types* }}{A}$ & $\begin{array}{c}A \text {-type } \\
\text { segregation } \dagger\end{array}$ \\
\hline 1 & A. edulis & Bretzloff & Illinois, U.S.A. & $0 \cdot 1-18$ & 915 & 1,2 & $379: 489:(47)$ \\
\hline 2 & A. bitorquis & Visscher & Netherlands & 20 & 64 & 2,3 & $41: 18:(5)$ \\
\hline 3 & A. bitorquis & Hagen & Netherlands & 10 & 50 & 5,6 & $23: 15:(12)$ \\
\hline 4 & A. campestris & W. Robbins & Illinois, U.S.A. & 13 & 78 & 2,4 & $22: 42:(14)$ \\
\hline 5 & A. edulis & Poppe & Belgium & 10 & 117 & 2,4 & $49: 48:(20)$ \\
\hline 6 & A. rodmani & Robinson & New York, U.S.A. & 45 & 38 & 3,4 & $19: 17:(2)$ \\
\hline 7 & A. campestris & Andersen & Minn., U.S.A. & 17 & 24 & 11,12 & $15: 7:(2)$ \\
\hline 8 & A. bitorquis & W. Robbins & Illinois, U.S.A. & 0.05 & 33 & 2,13 & $16: 13:(4)$ \\
\hline 9 & A. arvensis & Fergus & Penn., U.S.A. & 28 & 34 & $x, y$ & $13: 19:(2)$ \\
\hline 10 & A. campestris & Fergus & Penn., U.S.A. & 22 & 36 & $x, y$ & $11: 19:(6)$ \\
\hline 11 & A. campestris & Robinson & New York, U.S.A. & $0 \cdot 1-1$ & 34 & $x, y$ & $14: 4:(16)$ \\
\hline 12 & A. subrufescens & Benson & Mass., U.S.A. & 2 & 32 & $x, y$ & Uncertain \\
\hline 13 & A. arvensis & Sproston & Vermont, U.S.A. & 0.05 & 2 & - & \\
\hline 14 & A. campestris & Fergus & Penn., U.S.A. & $0 \cdot 1$ & 23 & $?$ & \\
\hline 15 & A. campestris & E. Robbins & Illinois, U.S.A. & & 15 & $?$ & \\
\hline 16 & A. campestris & Bumber & Illinois, U.S.A. & & 5 & $?$ & \\
\hline 17 & A. augustus & J. Raper & California, U.S.A. & 0.01 & 15 & - & \\
\hline 18 & A. sylvaticus & Benson & Mass., U.S.A. & $<0.001$ & 5 & - & \\
\hline 19 & A. abruptibulbus & Irbin & Mass., U.S.A. & 1 & 8 & - & \\
\hline 20 & A. bisporus & Watling & Scotland & 2 & 44 & - & \\
\hline 21 & A. subperonatus & Watling & Scotland & & 33 & - & \\
\hline 22 & A. bernardii & Watling & Australia & $<0.01$ & 31 & 15,16 & $15: 16:(0)$ \\
\hline 23 & A. campestris & Watling & Australia & & 26 & 17,18 & $13: 11:(2)$ \\
\hline 24 & A. campestris & Watling & Australia & $0 \cdot 01-0.1$ & 31 & - & \\
\hline 25 & A. bitorquis & L. Raper & Delaware, U.S.A. & $0 \cdot 01-0 \cdot 1$ & 39 & - & \\
\hline 26 & A. abruptibulbus & Halliwell & Mass., U.S.A. & 10 & 41 & $?$ & \\
\hline 27 & A. abruptibulbus & Kaye & Mass., U.S.A. & 2 & 35 & $?$ & \\
\hline 28 & A. campestris & Modigliani & New Hampshire, U.S.A. & 25 & 39 & - & \\
\hline 29 & A. abruptibulbus & Ullrich & Vermont, U.S.A. & 50 & 40 & - & \\
\hline 30 & A. rodmani & Ullrich & Vermont, U.S.A. & 1 & 39 & $x, y$ & $19: 17:(3)$ \\
\hline 31 & A. arvensis & C. Raper & New York, U.S.A. & & 50 & $x, y$ & $9: 3:(38)$ \\
\hline 32 & A. bisporus & Kenneth & Israel & 44 & 70 & - & \\
\hline 33 & A. bisporus & Kenneth & Israel & 30 & 98 & - & \\
\hline
\end{tabular}

* $x, y$, Types not identified. - and ?, Types not identifiable: -, no visible mating interaction occurred; ?, mating interaction ambiguous.

$\dagger$ Number in parentheses is the number of progeny which reacted with neither $A$ type.

Agaricus bisporus were studied for comparison with the stocks from nature. These included 16A, a strain obtained from J. P. San Antonio, U.S. Department of Agriculture, Agricultural Research Service, Beltsville, Maryland, U.S.A.; 70-2, a Campbell Soup Company strain supplied by R. E. Miller; and five strains used in a previous study (Raper et al., 1972): W, W9ade-his-:Nunk ${ }^{-}$, W9ade-his-:Wpro-, and the homokaryotic strains Wpro- and W9ade-his ${ }^{-}$. In addition, the so-called Stoller brown strain was used in some interfertility studies.

Representatives of all stocks studied are deposited with the American Type Culture Collection, accession numbers 34721 to 34864,24663 and 24665.

Cultural techniques and microscopic observations. Media and methods for the isolation and germination of spores, routine culturing, and observation of the nuclear content of cells were employed as previously described for $A$. bisporus (Raper et al., 1972). Spore size was determined by mounting spores in a lactophenol mounting medium [no. SR-1 in Mycology' Guidebook (1974)] and measuring a sample of 10 to 50 spores of each stock using a calibrated ocular micrometer and an oil immersion lens with phase optics.

Mating tests. Mating tests to detect heterothallism were carried out as described by Raper (1976a). Up to 10 progeny isolated from single spores were mated in all pairs and observed for visible evidence of interaction. The development of a macroscopically distinct white fluffy mycelium in the zone of contact and its occurrence in a pattern consistent with the segregation of alternative alleles at one or possibly two incompatibility loci was considered positive evidence of heterothallism. Where such a pattern could be interpreted, incompatibility types, e.g. $A x$ and $A y$, were assigned to members of the interacting groups within the initial sample. One or two representatives from each incompatibility group were then used as testers in matings 
with the remaining members of the sample to discern segregation of incompatibility alleles. Interaction between stocks was determined by mating one or two representatives of each incompatibility type from each stock in all paired combinations. Identification of incompatibility types was established as previously described (Raper, 1976a).

Evidence for heterokaryosis of mated mycelia was obtained either by demonstrating the nutritional competence of isolated hyphae derived from the mating of two complementing auxotrophs or by demonstrating the fruiting competence of mycelium isolated from the mating of two self-sterile mycelia. Details of these procedures were given previously (Raper et al., 1972; Raper, 1976a).

Fruiting tests. Fruiting competence of the various monosporous and mated mycelia was determined by tests performed at the Campbell Institute for Agricultural Research at Riverton, New Jersey, under the guidance of Dr R. E. Miller. A modified Till substrate was employed under conditions preventing crosscontamination as previously described for $A$. bisporus (Miller \& Kananen, 1972) except that the temperature after casing was $6{ }^{\circ} \mathrm{C}$ higher. Three replicates of each strain were tested. Fertility was indicated by fruiting or the formation of fruiting primordia (pinning) in at least one of the three replicates. However, failure to fruit did not necessarily indicate infertility.

Extracellular enzyme detection. The extracellular production of a number of enzymes was analysed on diagnostic solid media, generally according to the methods of Hankin \& Anagnostakis $(1975,1977)$ but with some modifications. Two or three progeny from each of the stocks were grown on the diagnostic media for 1 to 2 weeks. In each enzyme test all stocks were grown simultaneously for the same period of time. The recommended media for the detection of RNAase and DNAase did not support growth of Agaricus and so the standard minimal medium for Agaricus (Raper et al., 1972) with added RNA or DNA was used instead. Also, the saturated $\left(\mathrm{NH}_{4}\right)_{2} \mathrm{SO}_{4}$ solution used by Hankin \& Anagnostakis (1975) for precipitation of the proteins remaining after 1 week incubation on the gelatin test medium for protease did not work under our conditions, and instead we used a solution of $15 \mathrm{~g} \mathrm{HgCl}_{2}$ and $20 \mathrm{ml} 6 \mathrm{M}-\mathrm{HCl}$ in $100 \mathrm{ml}$ water, as recommended in Manual of Microbiological Methods (1957).

Isoenzyme tests. Comparative isoenzyme patterns for $\alpha$-esterase were determined by a modification of the method previously described for Mucor hiemalis (Havens, 1976). The liquid shake cultures, started with mycelia macerated for a few seconds in a Waring blender, were grown at $25^{\circ} \mathrm{C}$ for 2 weeks with subculturing to fresh medium [Difco Mycological Broth plus 3\% (w/v) yeast extract] after 1 week. Electrophoresis of protein extracts was carried out on vertical gels of $7.5 \%(\mathrm{w} / \mathrm{v})$ polyacrylamide in $0.1 \mathrm{M}$-Tris/boric acid/ EDTA at pH 8.9, with bromothymol blue as a marker. All gels were run for $4 \mathrm{~h}$ at $15 \mathrm{~V} \mathrm{~cm}^{-1}$ and less than $100 \mathrm{~mA}$. Protein extraction and staining were done according to the procedure described by Havens (1976).

\section{RESULTS}

Progeny from 33 of the 38 specimens of Agaricus collected from nature were analysed for a variety of characteristics and compared with several strains of cultivated $A$. bisporus. The specimens were identified originally on the basis of fruit-body morphology by their various collectors. Spores did not germinate in five of the specimens: two A. placomyces and one $A$. silvicola from Massachusetts, one $A$. campestris from Minnesota, and one $A$. arvensis from New York State. Spore germination in the remainder ranged from less than 0.001 to $50 \%$, and two to several hundred progeny were obtained from each of the 33 collections (see Table 1).

\section{Sexuality}

Each stock was first tested for its type of sexuality, i.e. whether homothallic or heterothallic. Cultivated $A$. bisporus was previously demonstrated to have a secondary form of homothallism in which self-fertility of single-spore isolates results from heterokaryosis and heteroallelism for a single mating type locus (incompatibility factor $A$ ): each spore when formed contains two haploid nuclei compatible for mating type (Raper et al., 1972). Agaricus bitorquis was shown to be heterothallic with unifactorial control: mating interactions are controlled by multiple alleles of the single incompatibility factor $A$. This was determined in an earlier study of the first five stocks listed in Table 1 (Raper, 1976a). Two $A$ incompatibility types ( $A$ types) segregated in the progeny of each stock. The five stocks were interfertile and contained six $A$ types, $A 1$ to $A 6$.

A comparable analysis of stocks 6 to 33 showed that 11 were heterothallic with unifactorial incompatibility. Altogether 16 of the 33 stocks appeared to be heterothallic on the 


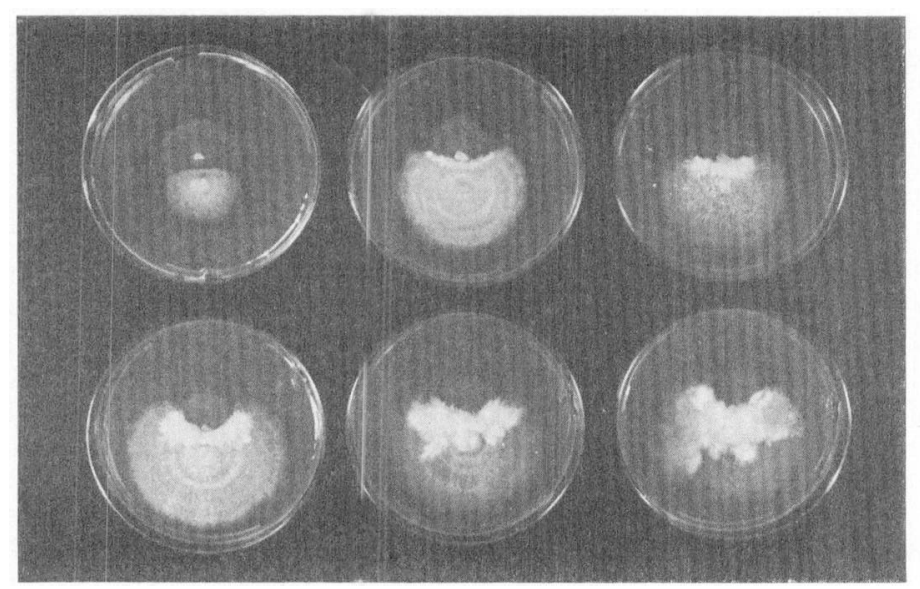

Fig. 1. Mating interactions in members of the genus Agaricus. The variability in positive mating interactions is illustrated by the variation in appearance of visibly distinct heterokaryotic mycelium developed in the zone of contact in compatible matings, all the same age, of various members of Agaricus. For comparison, an incompatible mating with no interaction is also shown (upper left plate).

basis of their pattern of visible interactions. These interactions were distinguished by the development of a white fluffy mycelium in the zone of contact of the two mated mycelia. The reactions varied considerably, as illustrated in Fig. 1. The pattern of sibling interaction within each stock was bipolar, that is siblings could be assigned to one of two types according to mating interactions: all pairings involving different mating types produced positive interactions; no pairings within the same type produced positive interactions. In each stock 0 to $75 \%$ of the progeny did not interact with testers from either group. These were considered inactive for reasons other than $A$-type incompatibility and were not analysed further.

\section{Visible interactions between stocks}

The majority of stocks that interacted visibly and thus appeared heterothallic in intrastock mating tests also interacted with one another. Representatives of the two mating types of each stock in all paired interstock combinations gave the pattern of interaction shown in Table 2. Stocks 1 to 8, 22 and 23 were completely interactive: either one or both mating types of each stock when mated with those of the others produced the visibly distinct mycelium characteristic of a positive interaction. Stocks 9, 30,10 and 12 showed a pattern of partial interaction with each other and with the fully interactive stocks; i.e. not all combinations compatible for mating type produced the distinct mycelium. Stock 11 (not shown in Table 2) did not mate with isolates of any other stock. Stock 31 gave relatively poor reactions in sibling matings and was not tested with other stocks.

\section{A types}

The identity of $A$ types segregating among the progeny of the 10 fully interactive stocks was determined through the above series of matings. In addition to the six parental mating types identified in stocks 1 to 5 (Raper, 1976a), seven new mating-type alleles were found in stocks 7, 8, 22 and 23 (Table 1). Even though the pattern of interaction indicated bipolar incompatibility, the expected $1: 1$ ratio of segregation for two alleles at a single locus occurred in only about half the stocks (Table 1). 
Table 2. Interstock mating and fruiting

\begin{tabular}{|c|c|c|c|c|c|c|c|c|c|c|c|c|c|c|}
\hline Stock & 1 & 2 & 3 & 4 & 5 & 6 & 7 & 8 & 22 & 23 & 9 & 30 & 10 & 12 \\
\hline 1 & $+F$ & $+F$ & $+\mathrm{F}$ & $+F$ & $+F$ & $+\mathbf{F}$ & $+F$ & $+F$ & + & + & $+o$ & $?$ & to & -0 \\
\hline 2 & & $+F$ & $+F$ & $+\mathrm{F}$ & $+F$ & $+F$ & $+F$ & $+F$ & + & + & $+o$ & $?$ & - & - \\
\hline 3 & & & $+F$ & $+F$ & $+F$ & $+F$ & $+F$ & $+\mathrm{F}$ & $+o$ & + & $+\mathbf{P}$ & $?$ & - & - \\
\hline 4 & & & & $+F$ & $+F$ & $+F$ & $+F$ & $+F$ & + & + & $+o$ & $?$ & -0 & - \\
\hline 5 & & & & & $+F$ & $+F$ & $+F$ & $+F$ & $?$ & $?$ & $+o$ & $?$ & - & - \\
\hline 6 & & & & & & $+P$ & $+F$ & $+F$ & + & $?$ & $?$ & $?$ & $?$ & - \\
\hline 7 & & & & & & & $+F$ & $+F$ & $+o$ & +o & $?$ & $?$ & $?$ & - \\
\hline 8 & & & & & & & & $+F$ & + & + & - & + & ?o & + \\
\hline 22 & & & & & & & & & +0 & + & $?$ & $+o$ & + & + \\
\hline 23 & & & & & & & & & & $+o$ & $?$ & $+o$ & + & + \\
\hline 9 & & & & & & & & & & & $+o$ & $+o$ & $+o$ & $?$ \\
\hline 30 & & & & & & & & & & & & +o & $+o$ & + \\
\hline 10 & & & & & & & & & & & & & $+o$ & $?$ \\
\hline 12 & & & & & & & & & & & & & & + \\
\hline
\end{tabular}

+ , Visible mating interaction; -, no visible mating interaction; ?, mating interaction ambiguous.

F, Fruiting; P, pinning; o, no fruiting or pinning; blank, not tested.

\section{Non-parental A types}

A low incidence of non-parental $A$ types was previously detected in the progeny of some crosses in stocks 1 to 5 . These were designated $A 7$ to $A 10$ (Raper, 1976a). Non-parental $A$ types were seen in only one stock of the current study. The progeny of stock 8 showed an initial segregation of three $A$ types in the ratio $16 A 2: 13 A 13: 2 A 14$. An expanded analysis of the first-generation progeny from this same stock, one year later, gave the unexpected ratio of 15A2:51 A13:22A14. However, four crosses involving different pairs of compatible progeny, two of $A 2 \times A 13$ and two of $A 13 \times A 14$, produced only parental $A$ types. The pooled segregation ratios in these second generations were $37 A 2: 72 A 13$ and $21 A 13: 19 A 14$ respectively. Perhaps the fruit body of the original collection contained the genomes of three instead of the usual two nuclei, at least for the chromosome carrying the incompatibility locus, so that segregation in the first generation was trisomic. Another possible but less likely explanation is a bipartite structure of the $A$ factor. In the latter case, two non-parental recombinant $A$ types would be expected to segregate and do so repeatedly; this did not occur in the analysis of stock 8.

The 10 fully interactive stocks thus had 13 parental and five non-parental $A$ types. $A$ types could not be assigned with certainty to the partially interactive stocks. They were therefore designated in each case as $A x$ and $A y$. Insofar as the mating types of these latter stocks could be tested, all were different from one another.

\section{Fruiting}

Homothallism was indicated in three stocks of $A$. bisporus, 20, 32 and 33, by the fruiting of monosporous isolates. In a sample of six isolates tested from stock 20 , one isolate fruited, four produced fruiting primordia (pinned) and one neither fruited nor pinned. Of six isolates tested from stock 32 , one fruited and five pinned. Of six tested from stock 33, one fruited, four pinned and one did neither. Single progeny from all the other stocks, which presumably all had four-spored basidia, did not fruit. An average of six isolates from each stock were tested in replicates of three. If fruiting had occurred it would have been considered meaningful; the negative results indicated either self-sterility or failure to meet specific requirements for fruiting under the test conditions used.

Fertility of the morphologically distinct mycelia that developed in compatible matings within the visibly interactive stocks was also tested. These mycelia were considered to be heterokaryotic and potentially fertile on the basis of the earlier study of stocks 1 to 5 (Raper, 1976a). In preparation for a fruiting test the presumed heterokaryon was 
subcultured from the contact zone of the mating and grown in solid culture medium for at least 2 weeks, during which it remained morphologically stable and distinct from the homokaryotic mates. An average of seven representative heterokaryons of the intra- and interstock matings was tested. The results are given in Table 2 . The sample was scored as $\mathbf{F}$ if any member fruited, $P$ if any member pinned but none fruited, and $o$ if none fruited or pinned. Heterothallism and interfertility for stocks 1 to 8 were confirmed by the pattern of fruiting obtained. The lack of fruiting in heterokaryons derived from the fully interactive stocks 22 and 23 and the partially interactive stocks 9, 30, 10 and 12 may have indicated infertility; but a note of caution against this interpretation is introduced by the fact that samples of 14 to 20 intrastock heterokaryons, obtained from compatible matings between different siblings of each of these stocks, also did not fruit. Perhaps the conditions for fruiting of these particular specimens were not met in the tests employed. The single exception, pinning in a mating between stocks 9 and 3, is notable.

The visibly distinct, presumed heterokaryons subcultured from 10 compatible matings within stock 11, which did not interact with other stocks, were tested and did not fruit. Mated mycelia from four other stocks in which mating interactions were not clear were also tested for fruiting. The tested mycelia were subcultured from the zone of contact in sibling matings within stocks 15, 16, 26 and 27; no fruiting occurred in samples from eight, one, four and three different matings respectively.

It was possible to test the interfertility of two of the homothallic stocks with strains derived from cultivated $A$. bisporus. Stocks 32 and 33 were found to contain nutritional deficiencies that segregated in the progeny of each: a combined methionine- and histidinerequiring auxotroph in the former and a histidine-requiring auxotroph in the latter. These auxotrophic progeny, which by themselves would not fruit, were tested for fruiting in matings with self-sterile complementing auxotrophs isolated by Dr R. E. Miller from the Stoller brown strain of cultivated $A$. bisporus. The method of selecting from such a mating a stable prototrophic heterokaryon that combines the nutritionally complementing nuclei of the two mates has been described previously (Raper et al., 1972). Stable prototrophic heterokaryons from 41 matings between auxotrophs of stock 32 and of the Stoller brown strain were tested for fruiting; two fruited and five pinned. A comparable fruiting test was not done for matings between stock 33 and cultivated $A$. bisporus, but a compatible interaction was indicated by the establishment of stable prototrophic heterokaryons in matings between complementing auxotrophs of these two bisporic stocks. The prototrophic heterokaryons were analysed by demonstrating the presence of the complementing nuclei in isolated hyphal tips as previously detailed (Raper et al., 1972).

The tests for mating interaction and fruiting, together, identified two groups with respect to type of sexuality: homothallic (stocks $20,32,33$ ), and heterothallic with control by a single multiply allelic incompatibility factor (stocks 1 to 8 , certain; $10,30,9,11,23,22$, 12 and 31, probable). These groups are designated Hom and Het respectively in Table 3.

Four groups with respect to interactivity (i.e. fruiting ability and mating interaction combined) were apparent: (i) eight fully interfertile heterothallics (stocks 1 to 8); (ii) six partially interactive heterothallics (stocks 10, 30, 9, 23, 22, 12); (iii) one homothallic, interfertile with cultivated $A$. bisporus (stock 32 ); and (iv) one homothallic, interactive and probably interfertile with cultivated $A$. bisporus (stock 33 ). These groups are designated I, I*, II and II* respectively in Table 3 . Types of sexuality and interfertility relationships could not be established for the remaining stocks.

\section{Nuclear content of cells}

A criterion of possible relevance to sexuality is the number of nuclei per cell. Fertile heterokaryons of stocks 1 to 5 were previously shown to be dikaryotic with each cell containing one nucleus from each of the two mated homokaryotic mycelia; unmated homokaryons were multikaryotic, with various numbers of nuclei per cell (Raper, 1976a). 
Dikaryosis is characteristic of the fertile mycelia of many basidiomycetes and is often accompanied by the formation of clamp connections at septa, but clamp connections have not been seen in the Agaricus species studied. Furthermore, in contrast to stocks 1 to 5 of wild Agaricus, the cultivated A. bisporus does not have a clearly distinguishable dikaryotic phase; the cells of both homokaryotic and heterokaryotic mycelia are multikaryotic (Raper et al., 1972). Dikaryosis, therefore, appears to be a frequent, but not constant, correlate of fertility in this genus.

Evidence for dikaryosis was sought in stocks 6 to 33 to provide some additional clue to the nature of sexuality in the wild collections. Cells of monosporous isolates and cells of presumed heterokaryons, where such were discernible, were examined for their nuclear number. The number of nuclei per cell was counted for 40 to 100 cells in mycelia of three different strains in each case.

Monosporous isolates of all of the stocks were multikaryotic, with numbers of nuclei per cell ranging from 1 to 15 , mostly in the 2 to 7 range. A possible exception was the bisporic stock 20: in a sample of 100 cells from four monosporous and self-fertile isolates, the number of nuclei per cell ranged from 2 to 9 but peaked bimodally at 2 and $4 ; 36 \%$ had 2 and $32 \%$ had 4 , and the nuclei generally appeared to be associated in pairs. This is suggestive of dikaryosis and is clearly different from the even distribution seen in monosporous isolates of the other stocks.

Dikaryosis seemed to prevail in the presumed heterokaryons of stocks 6,7 and 23 with 80,58 , and $65 \%$ binucleate cells, respectively; the nuclear number fell within the relatively narrow range of 1 to 4 per cell. Presumed heterokaryons from compatible matings in the other visibly interacting stocks examined, 8 to 12,22 and 30 , were multikaryotic and indistinguishable from the component homokaryons. The nuclear number of cells in identifiable heterokaryons of the stocks is indicated in Table 3. Monosporous isolates of the bisporic stocks are considered to be heterokaryotic on the basis of the earlier studies with cultivated $A$. bisporus in which homothallism was shown to be of a secondary type (Raper et al., 1972).

In summary, no evidence for dikaryosis was seen in monosporous isolates from any of the stocks with the possible exception of the bisporic, self-fertile stock 20. Dikaryosis predominated, with one exception, in fertile heterokaryons of the interfertile stocks 1 to 8 . Even so, the percentage of binucleate cells varied from 58 to $80 \%$. Fertile heterokaryons of the exceptional stock 8 had only $25 \%$ binucleate cells, well within the range of 0 to $30 \%$ seen in all homokaryons. Only one of the visibly interacting stocks in which fertility could not be demonstrated, stock 23, appeared to have dikaryotic heterokaryons. Overall, the nuclear analysis seemed to contribute little to a clarification of the sexual nature of the wild collections.

\section{Extracellular enzymes}

Several criteria unrelated to sexuality were subsequently applied in the examination of the collections. Among these was a comparative survey of extracellular enzymes. Each test detected the activity of an enzyme complex released by the growing mycelium on a substrate included in the culture medium. The extracellular production of nine types of enzyme was assayed for two or more progeny of most stocks. The enzyme profile obtained for each stock presumably reflected its characteristic ability to utilize various substrates in nature.

Substrates for the enzymes tested were amylose (in soluble starch, amylodextrin), lipid (polyoxyethylene sorbitan, Tween 20), pectin, protein (gelatin), RNA, DNA, urea, organic phosphate and cellulose. Differences between stocks were clear only for amylase, lipase, pectinase, RNAase, phosphatase and urease (see Table 3). No evidence for the extracellular production of cellulase was seen in any of the stocks. DNAase was detected in some of the stocks on the medium specified by Hankin \& Anagnostakis (1975), but that medium did not support growth of most specimens of Agaricus. In a subsequent test on a supportive medium, 
Table 3. Members of the genus Agaricus arranged in order of relatedness by comparison of traits

\begin{tabular}{|c|c|c|c|c|c|c|c|c|}
\hline \multirow[b]{2}{*}{$\begin{array}{c}\text { Stock } \\
\text { no. }\end{array}$} & \multirow[b]{2}{*}{$\begin{array}{l}\text { Fruit-body } \\
\text { morphology } \\
\text { of Agaricus }\end{array}$} & \multirow[b]{2}{*}{$\begin{array}{l}\text { Visible } \\
\text { mating }\end{array}$} & \multirow[b]{2}{*}{$\begin{array}{c}\text { Type of } \\
\text { sexuality } \dagger\end{array}$} & \multirow[b]{2}{*}{$\begin{array}{l}\text { Inter- } \\
\text { activity } \\
\text { group }\end{array}$} & \multirow[b]{2}{*}{$\begin{array}{l}\text { Nuclei/cell } \\
\text { in hetero- } \\
\text { karyons§ }\end{array}$} & \multicolumn{3}{|c|}{ Growth characteristics } \\
\hline & & & & & & $\begin{array}{c}\text { Vegetative } \\
\text { morphology }+\end{array}$ & $\begin{array}{l}\text { Preferred } \\
\text { temp. }\left({ }^{\circ} \mathrm{C}\right)\end{array}$ & $\begin{array}{l}\text { In liquid } \\
\text { culture }\end{array}$ \\
\hline 1 & edulis & + & Het & I & Dik & A & 30 & + \\
\hline 5 & edulis & + & Het & I & Dik & A & 30 & + \\
\hline 4 & campestris & + & Het & I & Dik & A & 30 & + \\
\hline 7 & campestris & + & Het & I & Dik & A & 30 & + \\
\hline 6 & rodmani & + & Het & I & Dik & A & 30 & + \\
\hline 2 & bitorquis & + & Het & I & Dik & A & 30 & + \\
\hline 3 & bitorquis & + & Het & I & Dik & A & 30 & + \\
\hline 8 & bitorquis & + & Het & I & Mul & A & 30 & - \\
\hline 10 & campestris & + & Het & $I^{*}$ & Mul & A & 30 & - \\
\hline 30 & rodmani & + & Het & $I^{*}$ & Mul & B & 30 & - \\
\hline 9 & arvensis & + & Het & I* & Mul & B & 24 & + \\
\hline 11 & campestris & + & Het & $?$ & Mul & B & 24 & + \\
\hline 23 & campestris & + & Het & $\mathrm{I}^{*}$ & Dik & A & 24 & \\
\hline 22 & bernardii & + & Het & $I^{*}$ & Mul & A & 30 & - \\
\hline 12 & subrufescens & + & Het & $I^{*}$ & Mul & A & 24 & - \\
\hline 31 & arvensis & + & Het & & & $\mathrm{E}$ & 30 & + \\
\hline 14 & campestris & - & ? & & & B & 30 & + \\
\hline 15 & campestris & - & $?$ & & & B & 30 & + \\
\hline 16 & campestris & - & $?$ & & & B & 30 & + \\
\hline 28 & campestris & - & $?$ & & & C & 30 & \\
\hline 24 & campestris & - & $?$ & & & A & 30 & \\
\hline 25 & bitorquis & - & $?$ & & & $\mathrm{D}$ & 30 & + \\
\hline 27 & abruptibulbus & - & $?$ & & & A & 30 & - \\
\hline 29 & abruptibulbus & - & ? & & & A & 24 & - \\
\hline 19 & abruptibulbus & - & $?$ & & & A & 24 & \\
\hline 18 & sylvaticus & - & $?$ & & & A & 24 & \\
\hline 17 & augustus & - & $?$ & & & A & 30 & - \\
\hline cult. & bisporus & - & Hom & II & Mul & F & 24 & + \\
\hline 32 & bisporus & - & Hom & II & Mul & $\mathbf{F}$ & 24 & + \\
\hline 33 & bisporus & - & Hom & II* & Mul & $\mathbf{F}$ & 24 & + \\
\hline 20 & bisporus & - & Hom & & Dik & F & 30 & + \\
\hline 13 & arvensis & - & $?$ & & & B & 30 & + \\
\hline 21 & subperonatus & - & $?$ & & & B & 24 & - \\
\hline 26 & abruptibulbus & - & $?$ & & & B & 24 & - \\
\hline
\end{tabular}

the enzyme was not detected, probably because most of the substrate DNA did not dissolve in this medium. Most stocks produced extracellular protease, but the production was extremely variable among progeny within stocks (variation occurred within 11 stocks). These three criteria were therefore considered unsatisfactory for distinguishing between stocks.

Overall comparison of the enzymes listed in Table 3 indicated a reasonable consistency among progeny within stocks and for the members of the intrafertile groups I and II. Besides the two or three progeny examined for each stock, 11 progeny each of stocks 4 and 11 were also tested to assess intrastock variability. Variability within stock 4 was evident only for lipase and within stock 11, only for pectinase. Two heterokaryons of stock 4 were also tested; these gave the same results as the homokaryons except in respect of phosphatase (the two heterokaryons were positive, while the 11 homokaryons were negative).

Isoenzyme patterns

A more precise enzyme test for distinguishing groups within the collection involved the electrophoretic separation of $\alpha$-esterase into patterns of isoenzymes. Attempts were made to 
Table 3 (cont.)

\begin{tabular}{|c|c|c|c|c|c|c|c|c|}
\hline \multirow{2}{*}{$\begin{array}{c}\text { Stock } \\
\text { no. }\end{array}$} & \multicolumn{6}{|c|}{ Extracellular enzymes $\|$} & \multirow{2}{*}{$\begin{array}{c}\text { Isoenzyme } \\
\text { pattern } \\
(\alpha \text {-esterase })\end{array}$} & \multirow{2}{*}{$\begin{array}{l}\text { Spore } \\
\text { size } \$\end{array}$} \\
\hline & Amylase & Lipase & Pectinase & RNAase & Phosphatase & Urease & & \\
\hline 1 & $(+)$ & & - & - & - & - & I & $\mathrm{Sm}$ \\
\hline 5 & $(+)$ & & - & - & - & - & I & $\mathrm{Sm}$ \\
\hline 4 & $(+)$ & \pm & - & - & - & - & I & $\mathrm{Sm}$ \\
\hline 7 & & $=$ & - & - & - & - & I & $\mathrm{Sm}$ \\
\hline 6 & $(+)$ & - & - & - & - & - & I & $\mathrm{Sm}$ \\
\hline 2 & $(+)$ & \pm & - & - & - & - & & $\mathrm{Sm}$ \\
\hline 3 & $(+)$ & + & - & - & - & - & I & $\mathrm{Sm}$ \\
\hline 8 & $(+)$ & \pm & - & - & - & - & & $\mathrm{Sm}$ \\
\hline 10 & + & + & - & + & + & - & & $\mathrm{Sm}$ \\
\hline 30 & + & + & & + & + & & & $\mathrm{Sm}$ \\
\hline 9 & + & & - & + & + & - & II & $\mathrm{Sm}$ \\
\hline 11 & + & + & \pm & + & + & + & $\mathrm{V}, \mathrm{IV}$ & $\mathrm{Sm}$ \\
\hline 23 & + & & - & + & + & - & & $\mathrm{Lg}$ \\
\hline 22 & + & + & + & + & + & & & $\mathrm{Lg}$ \\
\hline 12 & $(+)$ & + & - & \pm & + & + & & Lg \\
\hline 31 & + & + & \pm & - & + & & II & $\mathrm{Sm}$ \\
\hline 14 & + & + & - & + & - & & III & Lg \\
\hline 15 & + & + & - & - & + & & III & $\mathrm{Lg}$ \\
\hline 16 & & + & - & - & + & + & IV & $\mathrm{Sm}$ \\
\hline 28 & $(+)$ & + & - & - & + & - & & $\mathrm{Sm}$ \\
\hline 24 & + & + & - & - & - & & & $\mathrm{Sm}$ \\
\hline 25 & + & + & - & \pm & + & + & & $\mathrm{Lg}$ \\
\hline 27 & - & + & - & - & + & & & $\mathrm{Sm}$ \\
\hline 29 & - & + & - & - & + & - & & $\mathrm{Sm}$ \\
\hline 19 & $(+)$ & + & - & - & + & & & $\mathrm{Sm}$ \\
\hline 18 & $(+)$ & + & - & - & + & - & & Lg \\
\hline 17 & - & & - & - & - & + & & $\mathrm{Lg}$ \\
\hline cult. & + & + & - & - & + & & VII & $\mathrm{Lg}$ \\
\hline 32 & + & & - & - & + & - & VII & Lg \\
\hline 33 & - & + & - & - & + & & VII & Lg \\
\hline 20 & $(+)$ & + & - & - & + & - & II & $\mathbf{L g}$ \\
\hline 13 & $(+)$ & - & - & \pm & + & - & VI & Lg \\
\hline 21 & $(+)$ & + & - & + & - & & & $\mathrm{Sm}$ \\
\hline 26 & + & + & - & + & - & + & & Lg \\
\hline
\end{tabular}

$\uparrow$ Het, Heterothallic; Hom, homothallic; ?, test results inconclusive.

\$ See text for definition; ?, test results inconclusive.

$\S$ Dik, Dikaryotic; Mul, multikaryotic.

$\dagger \dagger$ See Fig. 3.

$\|+$, Enzyme present; $(+)$, enzyme present, but in small amount; \pm variation in enzyme production among progeny; - , no detectable enzyme.

II See Fig. 2.

analyse isoenzymes of several other enzymes, including alcohol dehydrogenase, malic dehydrogenase, glutamic dehydrogenase and tetrazolium oxidase, but none of these tests worked well. Relatively large amounts of total protein were required to assay these enzymes, and Agaricus grows poorly and slowly in liquid shake culture compared with other fungi which have been tested for these enzymes. Consequently, insufficient amounts were produced by the culture methods feasible for this study.

The analysis was limited to the stocks that grew reasonably well in liquid shake culture. Isoenzyme patterns for $\alpha$-esterase were obtained for three replicates of one or two progeny from each of the following stocks: 1,3 to 7, 9, 11, 13 to $16,20,31$ to 33. Stocks 2 and 25 which would grow in liquid culture were not tested. Seven strains of cultivated $A$. bisporus were analysed for comparison. In addition, the analysis of 14 and 16 isolates each of stocks 

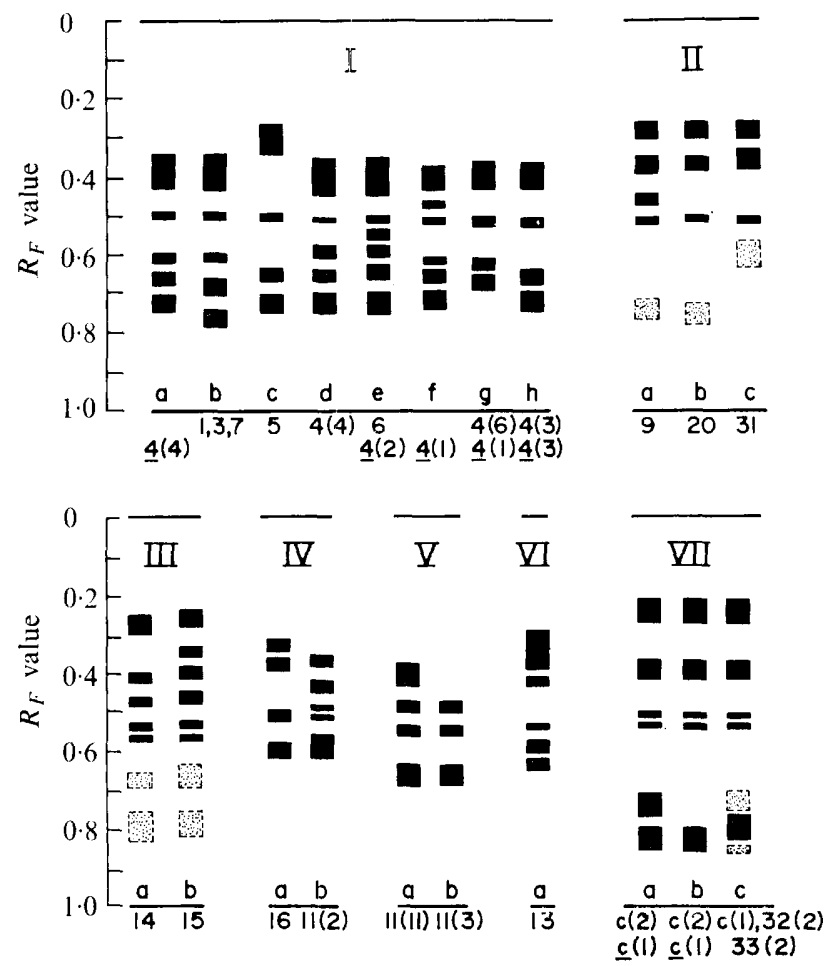

Fig. 2. Isoenzyme patterns for $\alpha$-esterase in members of the genus Agaricus. Major patterns I to VII are subdivided into minor patterns $a, b, c$ etc. The stocks displaying each pattern are indicated by their respective arabic numbers below the pattern. An unmodified number indicates the analysis of one monosporous isolate of that stock; an underlined number indicates the analysis of a heterokaryon derived from a compatible mating within the stock; a number in parentheses represents the number of different isolates cr heterokaryons from matings that were analysed. $\mathrm{c}$ indicates a monosporous (self-fertile) isolate of a strain of cultivated A. bisporus; $\mathrm{c}$ indicates a homokaryotic (self-sterile) strain derived from $A$. bisporus.

4 and 11 set the limits of intrastock variation. Eleven fertile heterokaryons derived by mating some of the tested homokaryons of stock 4 were also compared to see if significant differences could be attributed to the heterokaryotic state.

$\alpha$-Esterase separated into three to six stained bands on each gel, and seven general patterns with minor variations were seen. A pattern was distinguished by the relative positions of the bands with respect to one another and to the starting point of electrophoresis. Subgroups within patterns were defined primarily as a difference in the presence or positioning of one or two bands. The patterns, designated I to VII, each had from one to eight subgroups (Fig. 2). Intrastock variation was relatively minor and heterokaryosis had no apparent effect; all of the 13 homokaryotic progeny and 11 fertile heterokaryons of stock 4 fell within subgroups of pattern I. Furthermore, all of the tested stocks within the intrafertile group to which stock 4 belongs were also of pattern I. Most progeny of stock 11 showed pattern V, 11 of one subgroup and three of another; two of the 16, however, were of pattern IV, a pattern also displayed by stock 16 . All of the 11 strains from the interfertile bisporic stocks 32,33 , and cultivated $A$. bisporus showed pattern VII. The exceptional bisporic stock, 20, fell within a different pattern (II) along with stocks 9 and 31. Stocks 14 and 15 had pattern III in common, and stock 13 was alone in showing pattern VI. These observations are summarized in Table 3. 


\section{Growth characteristics}

During the course of this study it became evident that the collections of Agaricus could be grouped according to three characteristics of growth: vegetative (mycelial) morphology on solid medium; preferred temperature; and ability to grow in liquid shake culture. A sample of 2 to 16 progeny from each stock, cultured for a standard period of time, was examined according to these three criteria.

Vegetative morphologies could be assigned to six general categories, A to F. A representative of each type is illustrated in Fig. 3(a). Their general characteristics were as follows: A, regular surface, often with concentric rings, light grey or light brown with regular or slightly irregular edge; B, regular surface, dense, white, slightly irregular edge; C, patchy, streaked, white, irregular edge; $D$, raised surface in centre, white to light brown, irregular edge; E, entire surface domed with radiating slits, white, regular edge; F, somewhat patchy surface, light to dark brown, fairly regular edge, sometimes sectoring to produce fastgrowing white fluffy mycelium. The growth rate varied appreciably within and between stocks and the morphology varied somewhat within a given category, as illustrated for type A in Fig. $3(b)$, but generally the categories could be distinguished from one another. All the progeny of the eight interfertile heterothallic stocks shared the most common morphology (A). Progeny of the three bisporic stocks, 20, 32 and 33, had F-type morphology, similar to that of many strains of cultivated A. bisporus. Stock 20, however, seemed to be dimorphic with occasional sectoring, from the F-type morphology, of a fast-growing fluffy white mycelium. Such sectoring is sometimes seen in strains of cultivated A. bisporus which, altogether, vary quite widely in colonial morphology. This, perhaps, is not surprising in view of the selective procedures used to obtain different strains during the long period of cultivation of this species. Most of the other stocks had either A- or B-type morphologies except for stocks 28,25 and 31 which had types C, D, and E, respectively. The morphologies of the stocks are summarized in Table 3.

The preferred temperature for growth was analysed by comparing colony diameters of progeny from all stocks after 2 weeks incubation on solid medium at 24 and $30{ }^{\circ} \mathrm{C}$. As shown in Table 3, all of the eight interfertile heterothallic stocks (group I) grew faster at 30 than at $24{ }^{\circ} \mathrm{C}$. The preferred temperature for the other stocks was about equally divided between 30 and $24{ }^{\circ} \mathrm{C}$. The two homothallic stocks 32 and 33 grew best at $24{ }^{\circ} \mathrm{C}$, as did most strains of cultivated $A$. bisporus, whereas the other bisporic stock, 20, grew faster at $30^{\circ} \mathrm{C}$.

Only about half of the stocks would grow in liquid shake culture (Table 3 ). This characteristic was not related to the growth rate in a comparable solid medium at the same temperature. Most of the interfertile heterothallic stocks and all three homothallic stocks of $A$. bisporus, as well as the cultivated variety, grew in liquid medium.

\section{Spore size}

Spore size is commonly used in classification of species within Agaricus. Spore measurements revealed two categories of spore size: large, 6.6 to $12.0 \times 4.8$ to $7.8 \mu \mathrm{m}$; and small, 4.8 to $7.8 \times 4.2$ to $6.0 \mu \mathrm{m}$. As with most of the criteria applied to the collection, members of the intrafertile group I were similar: all had small spores. The two homothallic bisporic members of groups II and II*, for which there is evidence of interfertility with cultivated A. bisporus, had large spores, comparable to those of cultivated $A$. bisporus. Spores of the other bisporic and homothallic stock, 20, were also large. About half of the other stocks had large spores, including the three heterothallic stocks 12, 22 and 23 which interacted in matings with the intrafertile group I. The spore sizes for all stocks are summarized in Table 3. 

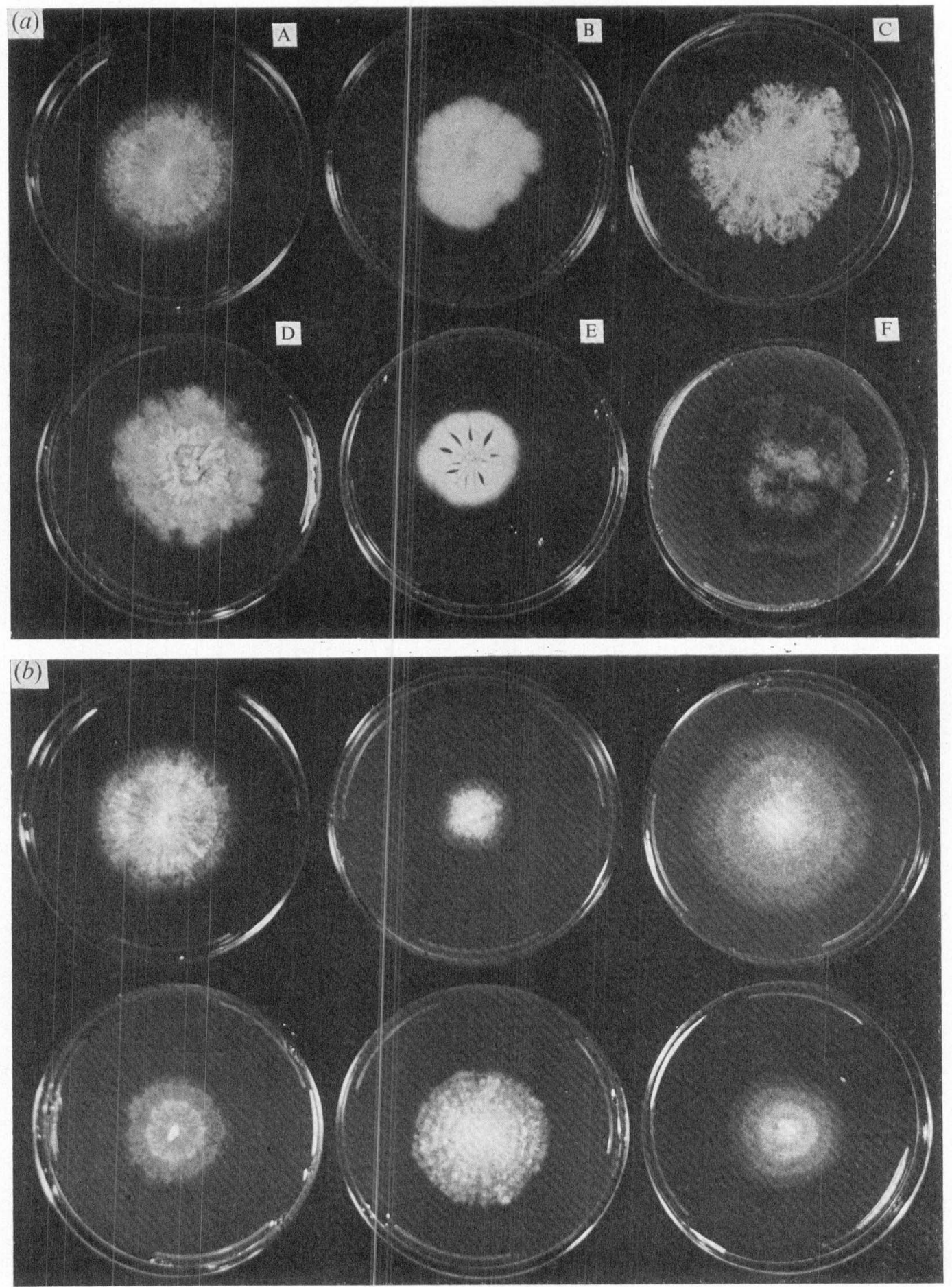

Fig. 3. Vegetative morphologies within Agaricus. (a) The array of types seen among the 33 stocks collected from nature. $(b)$ The range of variation in vegetative morphology within the single type A. 


\section{Synthesis of results}

Relationships within Agaricus have been studied by analysing 16 distinguishing characteristics for 33 members of the genus collected from nature and seven strains of cultivated $A$. bisporus. The traits for all members of the collection are compared in Table 3 and the stocks are listed in an order of relatedness for all 16 traits combined. Grouping by degree of relatedness was derived by a single-linkage cluster analysis in which each member of the collection was compared with all others for percentage similarity to the nearest $5 \%$, and the relationship between clusters was determined by calculating the average similarity of each pair of groups as they emerged in progression from the smallest, most closely related to the largest, least closely related. The method is described by Sneath \& Sokal (1973). The characteristics analysed were weighted equally in the calculation. The coefficient of similarity was based only upon those traits for which data were available for both members of the pair of stocks being compared. A trait for which there was a missing datum for either member of the pair was omitted in the calculation with a concomitant reduction in the divisor used for the overall comparison. The results for most criteria were binary but, whether binary or not, calculations were based on a match-versus-mismatch basis, with a match in a given category considered $100 \%$ similar and a mismatch $0 \%$ similar. There were four exceptions to this rule, and in each case the comparison was considered to be $50 \%$ similar: (i) under groupings for interactivity, I versus I* and II versus II*; (ii) under the extracellular enzyme amylase, $(+)$ versus + or - ; (iii) under the extracellular enzymes lipase, pectinase and RNAase, \pm versus + or - ; and (iv) under isoenzyme patterns of $\alpha$-esterase, IV versus V, IV.

The results of the calculation, which were put into a data matrix, are presented as a dendrogram in Fig. 4. All the stocks except three fall into six groups, I to VI, the members of which are interrelated by $65 \%$ similarity or greater; these are indicated by the solid connecting lines. Relationships at the level of $60 \%$ or less, indicated by the dotted connecting lines, are considered not significant in view of the fact that results of most criteria were two-state rather than multistate, and a near-50\% relationship for the two-state criteria would be expected on the basis of random variation. The six groupings are a conservative estimate.

Group I, made up of the interfertile and heterothallic stocks 1 to 8 , is most homogeneous: two members are $100 \%$ similar, two others are $95 \%$ similar and all members are interrelated on average at the $90 \%$ level. If the specimens of this group are to be considered members of the same species they would all be called by the name that takes precedence, Agaricus bitorquis (Quél.) Sacc. (see Raper, 1976a).

Group II includes all but one of the remaining specimens that were designated as heterothallic on the basis of visible mating interactions. They comprise all the partially interactive stocks of the interacting group $\mathrm{I}^{*}$ and one other; these are three $A$. campestris, $A$. rodmani, $A$. arvensis, $A$. bernardii and $A$. subrufescens, and they are inter-related by $65-85 \%$.

Groups III, IV and VI encompass all but two of those specimens about which nothing could be learned of their sexuality. Group III might be called the $A$. campestris group because all but one of its six members are called by that name. Similarly, Group IV could be referred to as the $A$. abruptibulbus group since three of its four members have that name. Group VI has only two members, $A$. subperonatus and an $A$. abruptibulbus, related at the $75 \%$ level.

Group V is composed of the four bisporic specimens, including the cultivated $A$. bisporus. The two specimens from Israel, collected in close proximity to one another but far from any mushroom farm, are related to each other and the cultivated strains by 90 to $100 \%$. The specimen from Scotland is least like the other three with a similarity of $75 \%$.

The three remaining members of the collection, a heterothallic $A$. arvensis (stock 31 ) 


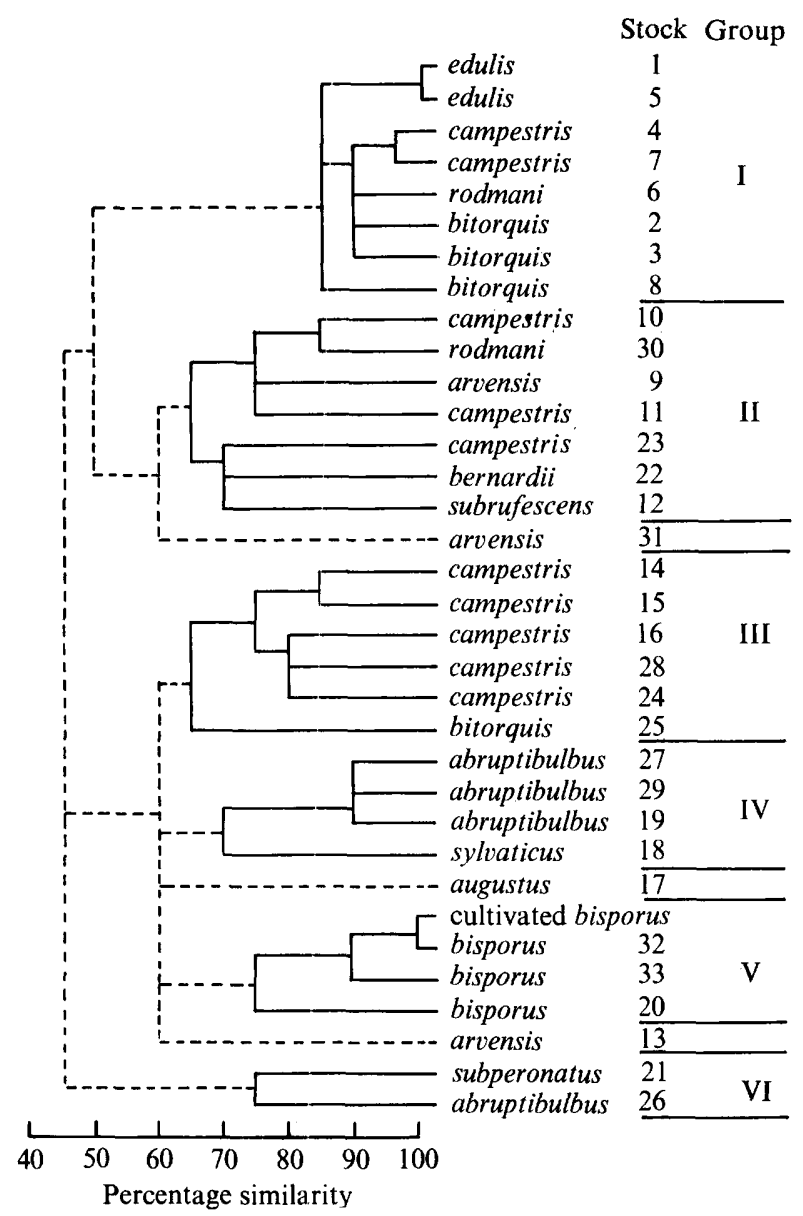

Fig. 4. Relationships among members of the genus Agaricus. The 33 specimens collected from nature plus cultivated $A$. bisporus are grouped on the basis of percentage similarity with respect to the 16 traits listed in Table 3. The degree of similarity was derived by a single-linkage cluster analysis as described in the text. The solid lines relate specimens within the region of similarity that is considered significant. The dashed lines indicate more tenuous relationships. The roman numerals designate specific groups of significantly related specimens.

and two others of unknown sexuality, A. augustus (stock 17) and A. arvensis (stock 13), could not be placed in any group. All groups inter-related in what is considered the nonsignificant range of 45 to $60 \%$.

\section{DISCUSSION}

A new concept of relationships in the genus Agaricus has begun to emerge from this study. By the comparative analysis of a broad spectrum of traits in many representatives of the genus, several groups were defined, most of which include two or more specific names assigned on the basis of fruit-body morphology. Previously, classification has been based on characteristics of the fruit body alone, including location and spore size. The inadequacy of these as sole criteria for definition of species was demonstrated here. For example, the name $A$. campestris, the designated type for the genus, appears in three of the six groups. Conversely, considerable variation in size and shape of fruit bodies was seen 
in laboratory crosses of stocks 4 and 5 and within each of these stocks (Raper, 1976b) yet they are both members of the interbreeding group (I). It is therefore not surprising to find such variation in nature. It should be noted, however, that several of the names given to the interfertile stocks of group I, A. edulis, A. bitorquis and A. rodmani, are considered by most taxonomists to be either synonyms or designations of subspecies (Singer, 1975).

The overall value of the several new criteria used for judging relationships was indicated by the fact that each varied within the entire sample yet remained relatively constant within populations of siblings. They differed both in degree of complexity and in relevance to an evaluation of kinship, yet all were weighted equally in the derivation of groupings. It could be reasonably argued, however, that some of the more complex characters, such as type of sexuality and interfertility relationships, should be weighted more heavily than the simpler ones such as preferred temperature for growth or production of an enzyme.

The ability to interbreed, as controlled by the genes of the mating system, seems most relevant to evaluation of kinship since it is the very basis for the reassortment of genetic determinants of all characteristics of the organism. The capability of interbreeding was demonstrated through laboratory tests in several stocks of the collection, but whether or not it actually occurs in nature can be assessed only indirectly. One such indication apparent from this study is the correlation within groups I and V between demonstrated interfertility and the homogeneity of all other characters analysed. Another indication of interbreeding in nature within group $\mathrm{I}$ is the wide geographical distribution of identical alleles of the $A$ incompatibility locus. One allele, $A 2$, was found in five stocks, three from Illinois, one from the Netherlands and one from Belgium; another, $A 4$, was found in stocks from Illinois, Belgium and New York State; and another, $A 3$, in stocks from New York State and the Netherlands. Intensive studies with other basidiomycetes, in which comparable distribution of incompatibility alleles has been observed, demonstrated the extreme rarity of the origin of new alleles through either mutation or intragenic recombination. The wide geographical distribution of identical incompatibility alleles within a species, therefore, is thought to result from their reassortment through interbreeding over great distances via wide dissemination of spores rather than from their independent origin (Raper, 1966).

The type of sexuality and pattern of interfertility could not be ascertained for 14 of the stocks in the sample. It was therefore necessary to rely upon the remaining criteria, most of which were shown to correlate well with interfertility in groups I and V, for the determination of relationships between these stocks. They were assigned accordingly to groups III, IV and VI. The pattern of interfertility was also unclear in group II. Although visible interactions were seen in most stocks of group II in matings with each other and with stocks of group I, complete interaction culminating in fruiting could not be demonstrated. This is perhaps indicative of a recent history of interbreeding between these stocks which are now in the process of becoming genetically isolated from one another.

Several aspects of the basic biology of the genus were revealed by this study. Two types of sexuality were identified, heterothallism and homothallism. The former predominated and the latter appeared to be of a secondary nature as was demonstrated earlier in cultivated A. bisporus (Raper et al., 1972). In both types, compatibility is controlled by a single genetic factor $(A)$ with alternative alleles; the $A$ factor in heterothallic forms is multistate with a demonstrated minimum of 18 alleles. The occurrence of non-parental $A$ types among the progeny of some crosses (Raper, 1976a) suggests the possibility that the incompatibility factor occupies more than a single locus and can be recombined. The cells of monosporous isolates are consistently multikaryotic, with the possible exception of the homothallic $A$. bisporus isolated in Scotland. Clamp connections, a common feature of fertile mycelia in other basidiomycetes, are not characteristic of this genus. There is also no evidence for extensive nuclear migration in compatible matings. Dikaryosis, however, another common feature of basidiomycetes, does occur in some members of Agaricus. The fertile hetero- 
karyons of about half of the specimens examined in this study had predominantly binucleate cells, and dikaryosis of fertile heterokaryons was proven in a previous study with stocks 1 to 5 of group I (Raper, 1976a).

An extension of this study should include attempts to answer several unresolved questions. Among these are: the genetic basis of dikaryosis, the structure of the incompatibility locus, the wide variation in spore germination, the failure of a fraction of progeny from the visibly interacting stocks to mate, and, perhaps most important, the type of sexuality and interbreeding capabilities of those stocks for which such knowledge is not now available. The absence of visibly distinct mating interactions and fruiting in laboratory cultures of these particular stocks, however, make the task difficult. Appropriate conditions for fruiting would have to be determined. Mating interactions could perhaps be ascertained by the tedious procedure of identifying prototrophic mycelium in the zone of contact between complementing auxotrophic mates, as was done previously in studies with $A$. bisporus (Raper et al., 1972), but each test of that kind would constitute a long-term study. Possibly, a microscopic analysis of hyphal anastamosis between stocks would also be helpful. Beyond this, an expansion of the number and type of criteria employed as well as an expansion of the sample itself should further clarify relationships within the genus.

Meanwhile, the current study may serve as a base, more comprehensive than any previously available, for the identification of additional specimens collected from nature. A first step in the identification of a specimen that looks like $A$. bitorquis, for example, might involve the comparative analysis of several of the more easily observed traits such as visible mating interactions between progeny, interaction with known strains of the species, nuclear number in heterokaryotic cells, spore size, preferred temperature for growth and extracellular phosphatase production. If these traits of the specimen match those of known members of the $A$. bitorquis group (I), then a certain identification can be accomplished through the more time-consuming tests for fruiting and interfertility. A similar procedure might be used for members of the $A$. bisporus group (V), but mating interactions would be far more difficult to ascertain. The assignment of specimens to other groups as defined by this study would be considerably less certain in the absence of knowledge about their sexual characteristics, but use of the other defining criteria should be helpful in the identification of such specimens.

The early part of this work was supported at Harvard University by a gift from Campbell Soup Company. Support has since been sustained by the Maria Moors Cabot Foundation for Botanical Research of Harvard University. The study was started in collaboration with Professor John R. Raper, husband of the senior author, deceased in May 1974. We gratefully acknowledge the valuable contribution of Dr Robert E. Miller of the Campbell Institute for Agricultural Research in performing the numerous fruiting tests, and also the contributions of Peter L. Havens and Lydia Davis in initiating and carrying out the isoenzyme studies. The co-operation of the many collectors who provided the specimens studied is also much appreciated.

\section{REFERENCES}

ElliotT, T. J. (1972). Sex and the single spore. Mushroom Science 8, 11-18.

FRITSCHE, G. (1976). Welche Möglichkeiten eröffnet der viersporige Champignon 'Agaricus bitorquis (Quél.) Sacc.' dem Züchter? (What potentialities does the four-spored mushroom 'Agaricus bitorquis (Quél.) Sacc.' offer to the breeder?) Theoretical and Applied Genetics 47, 125-131.

Hankin, L. \&. Anagnostakis, S. L. (1975). The use of solid media for detection of enzyme production by fungi. Mycologia 67, 597-607.
Hankin, L. \& Anagnostakis, S. L. (1977). Solid media containing carboxymethylcellulose to detect $\mathrm{C}_{\mathrm{x}}$ cellulase activity of micro-organisms. Journal of General Microbiology 98, 109115.

HAvens, P. L. (1976). Comparative zone electrophoresis and mating experiments in the taxonomy of Mucor hiemalis. Mycotaxon 4, 218-232.

Manual of Microbiological Methods (1957). Prepared by the Society of American Bacteriologists. New York: McGraw-Hill. 
Miller, R. E. (1971). Evidence of sexuality in the cultivated mushroom, Agaricus bisporus. Mycologia 63, 630-634.

Miller, R. E. \& Kananen, D. L. (1972). Bipolar sexuality in the mushroom. Mushroom Science $\mathbf{8}$, 713-718.

Mycology Guidebook (1974). Edited for the Mycological Society of America by R. B. Stevens. Seattle: University of Washington Press.

RAPER, C. A. (1976a). Sexuality and life-cycle of the edible, wild Agaricus bitorquis. Journal of General Microbiology 95, 54-66.

RAPER, C. A. $(1976 b)$. The biology and breeding potential of Agaricus bitorquis. Mushroom Science 9 (Part 1), 1-10.
RAper, C. A., RAPER, J. R. \& Miller, R. E. (1972). Genetic analysis of the life cycle of Agaricus bisporus. Mycologia 64, 1088-1117.

RAPER, J. R. (1966). Genetics of Sexuality in Higher Fungi. New York: Ronald Press.

RAPER, J. R. \& RAPER, C. A. (1972). Life-cycle and prospects for interstrain breeding of Agaricus bisporus. Mushroom Science 8, 1-9.

SINGER, R. (1975). The Agaricales in Modern Taxonomy, 3rd edn. Vaduz: J. Cramer.

SNEATH, P. H. A. \& Sokal, R. R. (1973). Numerical Taxonomy, The Principles and Practice of Numerical Classification. San Francisco: W. H. Freeman. 